\title{
AN ANALYSIS THE INFLUENCE OF SUBPROCESS IN PATIENT DISCHARGE TO A TIMELY MANNER DISCHARGE PROCESS IN XYZ HOSPITAL
}

\author{
Angela Geraldine Lilipaly \\ Master of Business Administration \\ Faculty of Business Administration and Humanities \\ Swiss German University, Indonesia
}

\begin{abstract}
Health care services everywhere have many process in their system. Discharge process is a last process during the patient stay in the hospital. In this process there are many division involve which would impact the time needed for each patient discharge to be completed. And this would also impact the waiting time of admiting other patient. Waiting time issues for accessing and providing healthcare services is also an issue in many hospital and is also identify by the leaders of one of the hospital in South Tangerang area (XYZ Hospital). At the time a patient is plan to be discharge, they expect a timely and quality discharge from their care provider. Hospital might have limitation on human resources, or be lack of standardization, preparation , communication, which create a bottleneck in the system. There are several process that patient have to go through when doctor concluded that the patient could be discharge: Nursing Discharge (X1): the time from patient has been prepare for discharge by physician to the time of nursing dicharge. Pharmacy Discharge (X)2: the time from excepting discharge prescribtion untill pharmacy discharge. Financial Discharge (X3) : the process of patient administration and payment. Discharge Education (X4) : time of education prior discharge given by the nurse and clinical pharmacist. While the Dependent variable is Time for patient discharge process (Y). The primary objective of this research is to explore and analyze those processes, where the hospital could identify which process is significant to improve, so the management of the hospital would focus the effort and support on those process/s; which then would make patient discharge more sufficient and will then also resulting the improvement of patient admission waiting time.The Statistic Model use for this research is Multiple Regression to examine the linear relationship between 1 dependent (Y) and 4 independent variable (X1, X2, X3, X4). Sample of inpatient patients which are discharge from the hospital. The sample of this research is by collecting secundary data; from December data which would be 248 patient discharge a month. By having this kind of measurement and analysis, it is expected that the hospital could identify which process is significant to improve, and the managment of the hospital would focus the effort and support on those process/s; which then would make patient discharge more sufficient and will then also resulting the improvement of patient admission waiting time. This research resulted that 3 out of 4 subprocesses influence patient discharge. The 3 subprocesses which impact significantly to patient discharge are: nursing, financial and education discharge processes.
\end{abstract}

Keywords: Business Development, Tender Proposal, Value Stream Mapping, Lean System 


\section{INTRODUCTION}

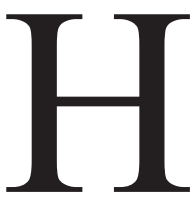

ealth care services everywere have many process in their system. Discharge process is a last process during the patient stay in the hospital. In this process there are many division involve, which would impact the time needed for each patient discharge to be completed. And this would also impact the waiting time of admiting other patient. Waiting time issues for accessing, providing healthcare services and discharging patient is also an issue in many hospital and is also identify by the leaders of one of the hospital in South Tangerang area (XYZ Hospital).

People require healthcare services from the moment they are born, and the demand for those services varies during their life time, therefore the volume of demand is almost the size of the human population (Khurma 2009). A hospital is an institution which provide health care to the community, which have a complex processes, dinamic, competitive, and complex multidicipline activities. Health care services everywere have many process in their system. There are inpatient processes and outpatient processes. Inpateint process is when patient is indicate to be admitted by physician to the hospital due to his/her ailment. The process for inpatient would include from admiting patient untill the patient is discharge from the hospital. This hospital leaders concern are also realted as describe in External Patient satisfaction survey in XYZ hospital from the 2013 until 2016 are showing decreasing of patient satisfaction on completing inpatient administrative process (Figure 1).

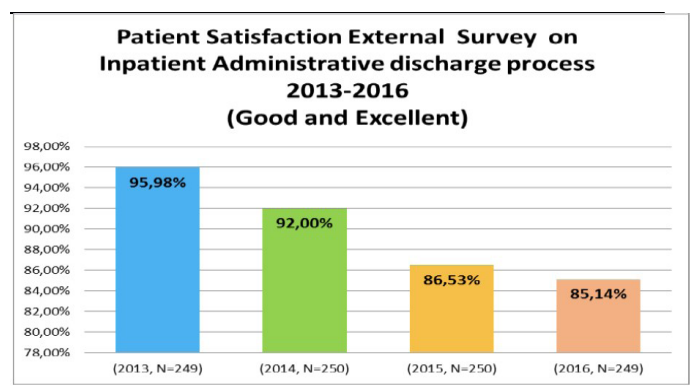

Figure 1. External Patient Satisfaction Survey on Completing inpatient administrative process of XYZ Hospital Source: Patient Satisfaction Survey- SEM Institute 2016.

Many hospital are or already attempted to improve their discharge process with the expectation to reduce discharge time for patients in order to open capacity for patients being admitted to the hospital. Patients would be admitted from Emergency Unit and also from polyclinics. These patients admission would depend on the bed availability in the hospital. To sufficiently prepare bed availability, patients who are ready to be discharge should be prepare sufficiently and appropriately. Discharge process is an interdisciplinary process, which need collaboration between nurses, doctors or medical specialist, pharmacy, administration and others. With these multidiscipline division, discharge process would result with many variation due to unpredictable human behaviour, and wide range of provided services.

As this hospital is committed to being a leading provider of health care services by delivering high quality outcomes for patients; and also strives hard to achieve excellent patient outcomes and sees patient safety as paramount to giving good patient care, by continuous improvement program focuses on clinical standards, customer feedback in line with developments in evidence based care and technology. This is the reason for leaders of the hospital aming the improvement of hospital discharge process. 
As the hospital is accredited by Joint Commission International (JCI), which is an International Hospital Accreditation Body base in Chicago, USA. The JCI standard require health care organization to be concern about quality and safety, particularly of Emergency Departement (ED) patients impacted by lack of access to inpatients beds, where hospital should consider the care it provides as part of an integrated system of services, health care practitioners and professionals, and levels of care, which make up a continuum of care. The goal is to correctly match the patient's health care needs with the services available, to coordinate the services provided.

Information is essential for making correct decisions about efficient flow of services to the patient. The hospital develops a process to manage the flow of patients throughout the hospital. JCI Standard ACC.2.2.1 (Access to care and continuity of care):

Emergency department (ED) crowding and high hospital occupancy rates can lead to boarding patients in the ED or creating temporary inpatient holding areas. Managing the flow of patients throughout their care is essential to prevent crowding, which can undermine the timeliness of care and, ultimately, patient safety. Effective management of system wide processes that support patient flow (such as admitting, assessment and treatment, patient transfer, and discharge) can minimize delays in the delivery of care.

Monitoring and improving these processes are useful strategies to reduce patient flow problems. Staff from throughout the hospital-inpatient units, ED, medical staff, nursing, administration, environmental services, risk management — can make a significant contribution to understanding and resolving problems in patient flow.

Measures and goals help identify impacts across units, reveal cycles and trends over time, and support accountability at all levels of the organization (JCI Standard 5th Edition).

The discharge process is the last process during the patient stay in the hospital. As a patient is discharged, they expect a timely discharge from their care provider. Hospital might have limitation on human ressources, or be lack of standardization, preparation , communication, which create a bottleneck in the system.

Discharge process would include and start from physician advise for patient to be discharge, then the nurse preperation and coordination, pharmacy preperation and drug reconciliation and also administration process on detail input of patients services.

There are 4 processes which was monitored for this research, and these 4 processes are would hypothetically impact the patient discharge process. The 4 process are:

- The time from patient has been advice for discharge by physician to the time of nursing completed administrative dicharge (Nursing Discharge process)

- The time from recieving discharge prescription untill pharmacy discharge (Pharmacy Discharge process)

- The time from process of patient administration completet to payment (Financial Discharge)

- The time of education prior discharge given by the nurse and clinical pharmacist (Discharge Education) 


\section{LITERATURE REVIEW}

\section{II.1. HOSPITAL}

Hospital around the world are searching for opportunities to improve efficiency. Efficiency is strongly linked to patient satisfaction. Hospital should start at the end of the patient journey by improving discharge efficiency. When patient are not efficiently discharge from hospital, they linger in beds even when medically fit to leave. In a full hospitals, this means delayed admissions in the emergency depatement and cancelled elective procedures as the rest of the hospital slows down to match the rate of patient discharge. In effect, a bottleneck at discharge undermines any other efficiency improvements in the hospital.

Preperation for discharge only begins when patient is already medically fit to leave the hospital. Therefore, timeconsuming tasks such as educating, scheduling follow up apointment, and arranging transportation may only began only when the patient could safely leave and thus, inevitably cause delays.

This schematic is simplified: many organisations are trying to complete some discharge preperation tasks earlier in the patient stay. However, despite hospital policies and redesign efforts, in most cases this reactive approach to patient discharge is still the general rule and results in endemic delays.

Many hospitals have already made considerable efforts to avoid discharge delays, but two obstacel limits their success. First, clinician deprioritise discharge preperation. Doctors and nurses are rightfully focused first on the acute clinical needs of patients. Many also do not draw a connection between discharging a healthy patient and providing high-quality, timely care to an acute patient waiting in the emergency departement. Clinician may also fail to understand their personal responsibility for discharge. For all these reasons, discharge is often placed at the bottom of a long list of clinician list (Johnson, 2013).

\section{II.2. NURSING DISCHARGE PROCESS}

Nursing discharge of patient who will require posthospital care, which address releven information and communication (Helle, 2006). Time pressures: including nurses being too busy in dealing with patients' physical problems which in turn delays timely progressing of the discharge planning process (Khurma, 2009).

The time frame of nurisng process for the patient to be discharge. This time frame is measured from the nurse identify the patient already been visit by the doctor, and the doctor has stated patients can be discharge; until the preperation process by the nurse is is complete. The hospital aim of this process is below 10 minutes (Hospital QPS , 2016).

\section{II.3. PHARMACY DISCHARGE PROCESS.}

The focus of discharge pharmacy has been address the needs of the patient being discharged with the goal of improving quality of life and health outcome (AmJ, 2015). Ensure preparation of inpatient discharge medication is complete. This process is measured from the time a prescription is review by inpatient pharmacy staff, until the medication is being completely check as according with doctor's prescription. The hospital is aming for discharge pharmacy is done within 45 minutes (Hospital QPS , 2016). 


\section{II.4. FINANCIAL DISCHARGE PROCESS}

By focussing on lengthy patient episodes it was found that "...four types of system obstacles prevented timely discharge; patient care issues, financial and legal issues, administrative issues and deficiencies in coordination between hospital and community personnel. Such nonmedical reasons for delayed discharges suggest that better planning may be beneficial (Khurma, 2009).

Monitoring the process of resolving administrative discharge, whereby the processing time is calculated from the start time until Final Time Billing. The Finance Discharge target is within 15 Minutes (Hospital QPS , 2016).

\section{II.4.1. DISCHARGE EDUCATION}

The "teach-back" process is a comprehensive interdisiplinary, evidence base strategy which can empower nursing staff to verify understanding, correct inaccurate information, and reinforce medication teaching and new home care skills with patient and families (Kornburger, 2013).

Monitoring a patient education process for discharge in the hospital by nurses and pharmacists. The time is measured from the patient's handed discharge card (which is given after payment was done) until education is given by nurses and pharmacist staff or pharmacy assistant. The education would include home medication and when to do follow up visit and other information regarding discharge. The aim for discharge education to patient is within 20 minuts (Hospital QPS , 2016).

\section{II.5. REDUCING AND OPTIMIZING THE CYCLE OF PATIENTS DISCHARGE IN A DMAIC APPROACH, VIJAY (2014)}

Hospital is the most important service industry. Today, everybody is concerned about the Quality of Health Care facilities and the term "Quality" becomes an essential element to combat competition in the Health care Environment. In the process of attaining Quality, each and every process in the Hospital needs to be optimized to the fullest satisfaction of the patients. One such process that drives direct attention from the patients is the preparation and the timely availability of discharge summary at the time when they are leaving the hospital. The success of any organization depends on its resource utilization and by ensuring the proper discharge process; we can assure patient satisfaction and also utilizing resources for more patient care.

The present study was conducted with two fold objectives using Six Sigma DMAIC Methodology viz: (i) To reduce the time interval between when a discharge order written by the physician and when the discharge summary is ready to be handed over to the patient; (ii) To find out which aspect of the current process would be in and out of scope to achieve the timely hand over of discharge summary to the patients.

This study was conducted at $\mathrm{KG}$ Hospital, India during the process of attaining hospital accreditation in the year 2010-2011. As a measure to improve the quality of services, one critical issue consists of delay in handover of discharge summary to the patients was identified and a cross functional quality management team was formed to 
address the underlying issues that might be causing the delays in discharging the patients. Accordingly, the team members explored various quality approaches and finally, decided to use DMAIC model with an objective to optimize the cycle time of patients discharge process. The study was conducted for the duration of 3 months and necessary process redesign was carried during this period for obtaining optimal results.

\section{II.6. DMAIC MODEL (DEFINE, MEASURE, ANALYZE, IMPROVE AND CONTROL MODEL)}

The methodological framework adopted in this study is based on DMAIC Model. The Quality tools and techniques and the strategies adopted in each phase of DMAIC to optimize the patients discharge process is described below:

\section{II.6.1. DEFINING THE PROBLEM}

Firstly, the exact critical issue to be investigated was clearly defined in this phase by the Chief Executive Officer (CEO) of the Hospital. The selection of that critical issue is based on the three key parameters viz. (i) Patient centered hospital mission; (ii) Past complaints received from the patients and; (iii) Historical patient satisfaction survey results.

\section{II.6.2. MEASURE THE CURRENT PROCESS}

The calculation of the current Sigma Level of error or defects in the discharging process was done with the goal of finding out how close the discharge process is to the target of six sigma standard deviation between the mean 234.35 minutes and the target 135 minutes. The results showed that in the 120 samples data obtained there were 85 discharges that fell above the target of 135 minutes, which is 0.95 or 1 standard deviation from the mean of 234.35 minutes. This may be because the existing discharge process contains many variables or special cases spread out throughout the process.

The mapping of the patients discharge process was carried out using process flow chart to analyze all the steps starting from the preparation of the discharge summary by the physician and continued with sequential activities until it is handed over to the patient.

The process comprising of a sequential steps starting from the discharge decision taken by the physician and ends with the timely handover of discharge summary to the patient. It was broken down into five logical sub processes viz:

1. Preparation of discharge notes by the attending physician or surgeon.

2. Processing of discharge notes by the ward secretary by appending the necessary laboratory reports.

3. Processing and typesetting of the discharge summary by the editor.

4. Completion of final discharge summary by the editor after proof read by the physician or surgeon.

5. Discharge summary ready to be handed over to the patient after signed by the physician or surgeon.

From the process mapping and the time study of each sub processes, it is found that six areas were identified as critical areas that may delay the timely handover of discharge summary to the Patients. Firstly, a delay might occur at the physician or surgeon's end in the rough preparation of discharge notes. Secondly, a delay might occur at the 
processing of the discharge notes by the ward secretary due to interruptions in getting the investigation reports. Thirdly, due to interruption in getting the completed discharge notes by the ward secretaries, there is a potential source of delay in sending the rough draft of discharge notes to the editor. The next source of delay may occur at the editores desk due to the centralized discharge summary preparation process. Even after the rough draft of discharge summary prepared by the editor, there might be a chance that the discharge report may hold up at the doctorse desk for getting his final approval and signature. Finally, even when the discharge summary is ready to be handed over to the patients, there might be a chance for delay in the process of getting clearance from the insurance or billing department.

\section{METHODOLOGY}

The framework model that will be investigated in this research study is about the effect of Nurse preparation time for patient discharge (X1), pharmacist preparation time for discharge medication prescription (X2), financial process time to complete patient's administration until payment (X3) and discharge education to prepare patient prior going home or to the next patient care (X4) toward time form nursing discharge until complete administration process $(\mathrm{Y})$, as describe below;

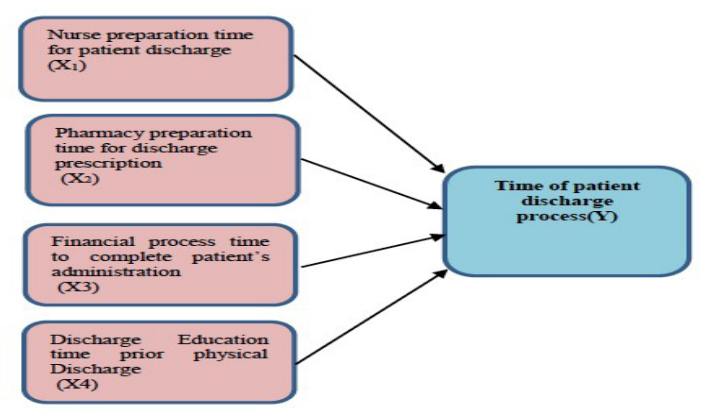

\section{III.1. STATISTIC MODEL}

The Multiple Regression Model: The Multiple Regression Model: to examine the linear relationship between 1 dependent (y) and 4 independent variable $(\mathrm{X} 1, \mathrm{X} 2, \mathrm{X} 3)$

$\mathrm{Y}=\beta 0+\beta 1 \mathrm{X} 1+\beta 2 \mathrm{X} 2+\beta 3 \mathrm{X} 3+\beta 4 \mathrm{X} 4$

$+\varepsilon$

Description Variables:

$\mathrm{Y}$ : Time for patient discharge process

X1 : Nurse preparation time for patient discharge

X2 : Pharmacy preparation time for discharge prescription

$\mathrm{X} 3$ : Financial process time to complete patient's administration discharge

X4 : Discharge Education prior physical discharge

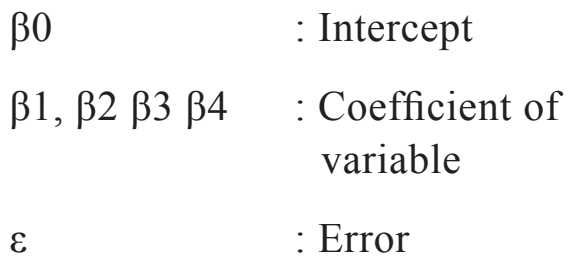

\section{III.2. MODEL HYPOTHESIS}

Based on the model above, the research made the hypothesis first before analysing the model. There were five hypotheses that the researcher made:

1st Hypothesis

H0 : Nurse, pharmacy, finance and education preparation time for discharge do not affect the time for patient discharge process $(\beta 1=\beta 2=\beta 3=\beta 4=0)$

H1 : Nurse, pharmacy finance and education preparation time for discharge together affect Time for patient discharge process (at least one $\beta$ is not zero) 
2nd Hypothesis

H0 : Nurse preparation time for discharge do not affect the time for patient discharge process $(\beta 1=0)$

H1 : Nurse preparation time for discharge affect Time for patient discharge process $(\beta 1 \neq 0)$

\section{3rd Hypothesis}

H0 : Pharmacy preparation time discharge do not affect Time for patient discharge process $(\beta 2=0)$

H1 : Pharmacy preparation time discharge affect Time for patient discharge process $(\beta 2 \neq 0)$

4rd Hypothesis

H0 : Finance preparation time

d_i_s_c_h_a_r_g_e__d_o_ _n_o_t a_f_f_e_c_t $\quad T$ i_m_e p_a_t_i_e_n_t__d_i_s_c_h_a_r_g_e p_r_o_c_e_s_s _ $\left(\_\beta 33_{-}={ }_{-} 0_{-}\right)_{-}$

H_1_ _ _ _ $\quad$ F_i_n_a_n_c_e_ p_r_e_p_a_r_a_t_i_o_n_ t t i_m_e d_i_s_c_h_a_r_g_e_ _ a f_f_e_c_t -T_i_m_e__f_o_r__p_a_t_i_e_n_t d_i_s_c_h_a_r_g_e - ( $\beta 33_{-} \neq \ldots \_$_ $)_{-}$

\section{RESULT AND FINDING}

Descriptive statistic was used to analyse the data by describing and showing the data in table, or graph. Descriptive statistic was done to explain the characteristic of discharge process time which include nursing discharge, pharmacy discharge, financial dicharge and patient education. This research was done on December 2016 with the total respondents were 248 patients discharge from the hospital. The result of descriptive analysis of characteristic respondents was explained on the graphs below.

Processing time form patient ready to be discharge untill discharge education prior physical discharge with an average of 142 minutes, median 125 minutes and mode 135 . This describing the discharge preperation would be more then 2 hours, which could be are for improvement

\begin{tabular}{|l|r|}
\hline Mean & 141,5282 \\
\hline Median & 125 \\
\hline Mode & 135 \\
\hline Range & 527 \\
\hline Minimum & 21 \\
\hline Maximum & 548 \\
\hline
\end{tabular}

Table 1. Descriptive Statistic Variable Y Source: Researcher's Own Elaboration, 2017

Time frame of nurisng process for the patient to be discharge have an average of 4 minutes. While the median and mode are 0 minute. Considering the hospital aim of this process is below 10 minutes, this time frame has already reach the expectation.

\begin{tabular}{|l|r|}
\hline Mean & 4 \\
\hline Median & 0 \\
\hline Mode & 0 \\
\hline Range & 180 \\
\hline Minimum & 0 \\
\hline Maximum & 180 \\
\hline
\end{tabular}

Table 2. Descriptive Statistic Variable X1

Source: Researcher's Own Elaboration, 2017

The pharmacy discharge process to ensure preparation of inpatient discharge medication is complete with an average of 37 minutes. And the median is 30,5 minutes and the the mode is 35 minutes. This process is measured from the time a prescription is review by inpatient pharmacy staff, until the medication is being completely check as according with doctor's prescription. Considering the hospital is aming for discharge pharmacy is done within 45 minutes, 
the time in completeing this process has reach the targeted time.

\begin{tabular}{|l|r|}
\hline Mean & 36,48387 \\
\hline Median & 30,5 \\
\hline Mode & 35 \\
\hline Range & 196 \\
\hline Minimum & 1 \\
\hline Maximum & 197 \\
\hline
\end{tabular}

Table 3. Descriptive Statistic Variable X2 Source: Researcher's Own Elaboration, 2017

Monitoring the process of resolving administrative discharge, whereby the processing time is calculated from the starting time of admin process until biling is final with an average of 25 minutes, median 12 and most frequent mode is 2 minutes. Considering the finance discharge target is within 15 Minutes, this would still be area for improvement

\begin{tabular}{|l|r|}
\hline Mean & 26,69758 \\
\hline Median & 17 \\
\hline Mode & 1 \\
\hline Range & 198 \\
\hline Minimum & 0 \\
\hline Maximum & 198 \\
\hline
\end{tabular}

Table 4. Descriptive Statistic Variable X3

Source: Researcher's Own Elaboration, 2017

Monitoring a patient education process for discharge by nurses and pharmacists with an average of 27 minutes, median 17 minutes and mode 1 minutes. The time is measured from the patient's handed discharge card (which is given after payment was done) until education is given by nurses and pharmacist staff or pharmacy assistant. The education would include home medication and when to do follow up visit and other information regarding discharge. Considering the aim for discharge education to patient is within 20 minuts, this is area for improvement

\begin{tabular}{|l|r|}
\hline Mean & 26,69758 \\
\hline Median & 17 \\
\hline Mode & 1 \\
\hline Range & 198 \\
\hline Minimum & 0 \\
\hline Maximum & 198 \\
\hline
\end{tabular}

Table 5. Descriptive Statistic Variable X4

Source: Researcher's Own Elaboration, 2017

\section{IV.1. INFERENCE STATISTIC}

This statistic methode will help to establish relationships among variables and draw conclusions therefrom. In this research, the researcher tried to find out the influencing of time frame process of nursing, pharmacy, finance and education discharge process as independent variables towards processing time form patient ready to be discharge untill education completed as dependent variable. The researcher used multiple regressions in order to find the influence of each independent variable to dependent variable. The result of this research was establish by taking sample of patient discharge process of 248 patients.

\section{IV.2. F TEST ANALYSIS}

By looking on ANOVA table above, it showed that the model of this research was fit. It can be seen from the value of F-stat is higher than F-table which was 31,166 > 2,45 Moreover, the value of significance $\mathrm{F}$ was lower than $\alpha$ too. If the value of significance on ANOVA table was below 0.05 , it indicated that the regression model can be used to predict the independent variable. Because of F-stat $>$ F-tabl, it meant that the researchers should reject $\mathrm{H} 0$ and accept $\mathrm{H} 1$ as stated in the hypothesis before. 


\subsubsection{T test Analysis}

4.2.2.1 X1, is significant because P-value 2,5673E-05 $<0,05(\alpha)$

4.2.2.2 $\mathrm{X} 2$, is not significant because $\mathrm{P}$-value $0,0543998>0,05(\alpha)$

4.2.2.3 X3, is significant because P-value $2,7519 \mathrm{E}-14<0,05(\alpha)$

4.2.2.4 $\mathrm{X} 4$, is significant because P-value 9,8629E-10<0,05 $(\alpha)$

The result of T-test analysis showed that 3 of independent variables were significant to dependent variable. It can be seen from the value of P-value for 3 variable were higher than $\alpha$ means. The 3 independent variables are : X1, X3 and $\mathrm{X} 4$

While 1 of the independent variable X2 was not significant.

After analyzing all of the result, the appropriate model for this research was

First, the intercept value is 75,629 , meaning that 75,629 is the estimation of the average of Time for patient discharge process when the explanatory variables $(\mathrm{X} 1, \mathrm{X} 2, \mathrm{X} 3$ and $\mathrm{X} 4)$ remain the same or zero. Second, the finding regarding each explanatory variable's (slope) indicated that X1, X3 and X4 were statistically significant different form zero where the coefficient value of X1 was 1,151, X3 was 1,001 and X4 was 0,959 . The value 1,151 indicated that any changes in nurse preparation time for patient discharge will increase discharge process variable by 1,151 . And the value 1,001 indicated that any changes in financial process time to complete patient's administration discharge will also increase discharge process variable by 1,001 . The value
0,959 of education discharge will also increase patient discharge. Meanwhile, the value 0,292 indicated that pharmacy discharge process will not increase discharge process.

\section{IV.3. X1 IS SIGNIFICANT AND} THE CORRELATION IS POSITIVE If X1 is increased $\rightarrow \quad \gamma$ Y would also increased, and

If $\mathrm{X} 1$ is decrease $\rightarrow \succ \mathrm{Y}$ would also decrease.

\section{IV.4. X2 IS NOT SIGNIFICANT}

AND SO THERE IS NO CORRELATION

If X2 is increased $\rightarrow \quad \succ Y$ would be constant (not be impacted)

If $\mathrm{X} 1$ is decrease $\rightarrow \quad \gamma \mathrm{Y}$ would be constant (not be impacted)

IV.VI. X3 IS SIGNIFICANT AND THE CORRELATION IS POSITIVE.

If $\mathrm{X} 3$ is increased $\rightarrow \quad \gamma \mathrm{Y}$ would also increased, and

If $\mathrm{X} 3$ is decrease $\rightarrow \quad \gamma \mathrm{Y}$ would also decrease

\section{IV.5. X3 IS SIGNIFICANT AND THE CORRELATION IS POSITIVE} If X3 is increased $\rightarrow \quad \succ Y$ would also increased, and

If X3 is decrease $\rightarrow \succ Y$ would also decrease

\section{CONCLUSION}

This last chapter will describe conclusion and recomendation on related to the purpose of this study that has been investigated by researchers through data analysis in the previous chapters. 
1. Nursing discharge process has a positive significant impact on patient discharge process time

2. Pharmacy discharge process has no impact on patient discharge process time

3. Financial discharge process has a positive significant impact on patient discharge process time

4. Education discharge process has a positive significant impact on patient discharge process time

The objective of this reasearch is to explore and analyse those processes, where the hospital could identify which processes are significant to improve, so the management of the hospital would focus the effort and support on those processes.

\section{V.1. RECOMMENDATIONS}

Through this research the subprocesses which would influence the patient discharge time can be determine. Nursing discharge process, finance discharge process and discharge education should be the focus of managment of the hospital to put effort and support; so that patient discharge could be more suffucient and in a timely manner. And pharmacy discharge should not be the focus on improving discharge process.

With this focus patient discharge process would be more sufficient and will then also resulting the improvement of patient admission waiting time.

\section{REFERENCES}

Ajami, Ketabi (2007), An Analysis of the average waiting time during the patient discharge process at Kashani Hospital in Esfahan, Iran: a case study. Health Information Management Journal, Vol. 36, Issue. 2, pp. 37-42.

Allen, Tseng, Swanson, McClay (2010), Improving the Hospital Discharge Process with Six Sigma Method. Journal Quality Engineering, Vol. 22, Issue. 1, pp. 13-20

Ametlli, Vanda (2010), Improving Inpatient Discharge Process To Reduce Readmission. Retrieved from https://docs.google.com/ viewer?url=http $\% 3 \mathrm{~A} \% 2 \mathrm{~F} \% 2 \mathrm{Fwww}$.iise.

Calemine (2015), Development of discharge pharmacy service. American Jurnal Health System Pharmacy, Vol. 72, Issue. 22, pp. 1936-1938

El-Eid, Kaddoum, Tamim, Hitti (2015), Improving Hospital Discharge Time, A succesful Implementation of Six Sigma Methodology. Journal of Medicine, Vol. 94, No. 12.

Evans \& Lindsay (2014), Managing for Quality and Performance Excellence. Cengage Learning, South Western: Australia.

Hellesø, Ragnhild (2006), Information on handling in the nursingdischarge note. Journal of Nursing. Journal of Clinical Nursing, Vol. 15, Issue. 1, pp. 11-21.

Khurma (2009), Analysis, Modeling and Improvement of Patient Discharge Process in a Regional Hospital (Master's Thesis). Retrieved from https://docs.google.com/ viewer?url=https $\% 3 \mathrm{~A} \% 2 \mathrm{~F} \% 2 \mathrm{Fscholar}$. uwindsor.ca $\% 2 \mathrm{Fcgi} \% 2 \mathrm{Fviewcontent.}$ 
Kornburger (2013), Using "teach back" approach to improving discharge process Jurnal of Pediatric Nursing. Journal of Pediatric Nursing, Vol. 28, Issue 2, pp. 282-91.

Montgomery (2013), Statistical Quality Control. John Wiley \& Sons. Arizona: USA

Pysdek \& Keller (2013), The Handbook for Quality Management. McGraw-Hill, New York: USA
Sekaran \& Bougie (2013), Research Methodology. John Wiley, West Sussex: UK

Vijay (2014), Reducing and Optimizing the cycle time of patients discharge process a hospital using six sigma DMAIC approach. International Journal for Quality Research, Vol. 8, Issue. 2, pp. 169-182. 